\title{
Farhad Zare Kordshouli, Akbar Mohammadi. « Yāftehāyei tāzeh az doreh hakhāmaneshi dar mohavateh Miyān Jādehei-e Pasargad / New Achaemenid findings of Pasargad Mianjade'i »
}

\section{Kourosh Mohammadkhani}

\section{(2) OpenEdition}

\section{Journals}

Édition électronique

URL : http://journals.openedition.org/abstractairanica/45546

DOI : 10.4000/abstractairanica.45546

ISBN : 1961-960X

ISSN : 1961-960X

Éditeur :

CNRS (UMR 7528 Mondes iraniens et indiens), Éditions de l'IFRI

\section{Référence électronique}

Kourosh Mohammadkhani, « Farhad Zare Kordshouli, Akbar Mohammadi. « Yāftehāyei tāzeh az doreh hakhāmaneshi dar mohavateh Miyān Jādehei-e Pasargad / New Achaemenid findings of Pasargad Mianjade'i » », Abstracta Iranica [En ligne], Volume 37-38-39 | 2018, document 51, mis en ligne le 30 décembre 2018, consulté le 26 septembre 2020. URL : http://journals.openedition.org/ abstractairanica/45546 ; DOI : https://doi.org/10.4000/abstractairanica.45546

Ce document a été généré automatiquement le 26 septembre 2020.

Tous droits réservés 
Farhad Zare Kordshouli, Akbar Mohammadi. « Yāftehāyei tāzeh az doreh hakhāmaneshi dar mohavateh Miyān Jādehei-e Pasargad / New Achaemenid findings of Pasargad Mianjade'i »

Kourosh Mohammadkhani 


\section{RÉFÉRENCE}

Farhad Zare Kordshouli, Akbar Mohammadi. « Yāftehāyei tāzeh az doreh

hakhāmaneshi dar mohavateh Miyān Jādehei-e Pasargad / New Achaemenid findings of Pasargad Mianjade'i », Pazhjuheshhāy-e Bāstānshenāsi Modares (Modares Archaeological

Research), vol. 5, no. 9, Spring \& Summer 2013 [2014], p. 82-97.

Dans le cadre du «Centre de Recherche de Pasargades », et avec son soutien, plusieurs études ont été entreprises ces dernières années dans la région de Pasargades, donnant lieu à des mémoires de Master en archéologie. Cette étude résume l'un d'eux, portant sur l'analyse des photos aériennes, la prospection archéologique et quelques sondages pour définir les limites d'un site à5,5km de Pasargades nommé « Tépé Miyān Jādehei », ("Tépé entre les deux routes ») sur l'autoroute Shiraz-Isfahan. Il couvre une superficie d'environ 35 hectares et est composé de neuf ensembles construits. Les céramiques ressemblent à celles de Pasargades et des sites achéménides de la vallée de Tang-e Bolaghi. Dans cette étude préliminaire les auteurs suggèrent de reconnaître dans ce site, qui était en dehors de la ville de Pasargades, était un lieu de stockage des produits agricoles pour soutenir la population de Pasargades.

\section{AUTEURS}

\section{KOUROSH MOHAMMADKHANI}

Université Shahid Beheshti, Téhéran 